\title{
Cooperation and Game between Producers and Managers Based on the Linear Contract
}

\author{
Xianglan Wan \\ School of Science, Hubei University of Technology, Wuhan 430068, China \\ Correspondence should be addressed to Xianglan Wan; wanlan415@sohu.com
}

Received 23 February 2014; Accepted 16 June 2014; Published 26 June 2014

Academic Editor: Samir Saker

Copyright (C) 2014 Xianglan Wan. This is an open access article distributed under the Creative Commons Attribution License, which permits unrestricted use, distribution, and reproduction in any medium, provided the original work is properly cited.

\begin{abstract}
There is a cooperative game between the manager and the producer in the enterprise. In this paper, we firstly construct the cooperative game model based on the principal-agent theory. Under the conditions of Nash equilibrium and linear contract, the paper calculates the net income of the client, the total risk and welfare of the agents when the agents have the cooperation or not. The result shows that the correlation coefficient between their output has a direct relationship with the cooperation. Secondly, according to the power distribution theory another model is developed. We analyze the game process and critical state. Furthermore, we deduce the share proportion of the profit and the control size when they have the cooperation. Finally, we summarize all the research achievements, which are of universal significance for the practical cooperation game problems.
\end{abstract}

\section{Introduction}

Enterprises are the sites of economic men to seek their own interests, and then an enterprise contract is formed between physical capital owners and nonphysical ones $[1,2]$. The contract is not only the concept in law; it is also an economic one. The people who take part in signing contracts with material capital owner are divided into two kinds: one kind is managers and also operators; another one is producers (workers) who are directly engaged in production and labor. Managers and producers have their common interests, namely, the enterprise profit for them, which is the basis of their cooperation. At the same time, under meeting participation constraint conditions an enterprise contract is formed to achieve their own interests. Therefore, the two sides are playing a game in the framework of cooperation [3-6]. The game is mainly about that the producer seeks opportunities while the manager constrains him to do so. This paper argues that the contradiction and conflict between stakeholders are an objective existence, but they will gradually achieve the benefit equilibrium through continuous bargaining games. Balanced interest of stakeholders is the driving force of enterprise's long-term health development [7-9].
Game analysis about stakeholders at home and abroad is mainly concentrated in the following respects. (1) The first respect is the conflict and game equilibrium of stakeholders, including mainly the fact that Jing thinks that multiple interests of the game between stakeholders exist in the process of corporate governance; stakeholder interests equilibrium is the basic motive power to improve corporate performance [10], Wang analyzes the stakeholders financial interest conflicts from the perspective of game theory [11], Liu puts forward the moral game to seek the effective interaction between interests and moral for the government and enterprises [12], and Jiao analyzes the conflict and game of the interests between the managers and the shareholders in company acquisition and antiacquisition activities and eventually finds out the legal solutions to solve the problem [13]. (2) The second respect is the cooperative game between the enterprise stakeholders, including mainly the fact that Ariel Rubinstein raises the alternating offers model to grind out cooperative game equilibrium solution [14], Xu thinks the game between stakeholders is cooperative and the emphasis is the collective rationality, efficiency, fairness, and equality [15], Zhao demonstrates the uniqueness of subgame refined Nash equilibrium solution by using the cooperative game model [16], Sun et al. start from the classification of stakeholders 
and on the basis of the Nash equilibrium build a cooperative game model from a moral perspective, and then come to the conclusion that the stakeholders are the combination of economic and moral men; they should serve collectivism as the principle and aim at the harmonious development of society when pursuing the maximum benefits [17].

The above game analysis about the stakeholders mainly focuses on the conflict and the balance of stakeholders interests from the angle of management by using the research paradigm of modern game theory. However, this paper constructs the cooperative game models of two interest groups about the producers and managers according to the principalagent and the power distribution theory, respectively. We concluded that, under the principal-agent theory, the correlation coefficient between their outputs has a direct relationship on the cooperation between the producer and the manager. Under the power distribution theory, there is an obvious correlation between whether producers and managers will cooperate and the ratio of profit distribution. Moreover, we calculate their respective optimal share and control size when they cooperate.

The remainder of this paper is organized as follows: based on the principal-agent theory a cooperative game model is established in Section 2. We calculate the benefits and the risks of the producer and the manager when they have cooperation and no cooperation, respectively. Based on the power distribution theory another model is established in Section 3. We deduce the optimal share proportion of the profit and the control size when they have the cooperation. Finally, Section 4 concludes with some discussions.

\section{Cooperative Game Model Based On Principal-Agent Theory}

In the company's production, capital group as the client, they coordinate the activities between agents through the establishment of production system; the agents are willing to obey the command or coordinate of the client due to the commitment in the signed contract. If agents do not obey the command, this means that they will give up the contract with the company. Capital group is composed of investors in the company; they as material capital owners become the principal. Labor group consists of production staff and management personnel; they become the agents in the firm. The formation of the contractual relationship between the clients and the agents in the company provides the conditions for the agents cooperation. Here comes a model to explain the process of cooperation and game between the agents $[18,19]$.

This paper discusses the situation of a client with two agents; the two agents are the producer and manager, respectively. Assume that the client is risk-neutral and two agents are risk-averse with CARA's risk preference, which can be represented in a negative exponential utility function:

$$
U_{i}\left(w_{i}, a_{i}\right)=-e^{-\eta_{i}\left[w_{i}-\psi_{i}\left(a_{i}\right)\right]} .
$$

Among them, $a_{i}$ represents the agent's effort level, $\eta_{i}$ represents the absolute risk aversion coefficient, $w_{i}$ represents monetary compensation, $\psi_{i}\left(a_{i}\right)$ is a strictly increasing and convex cost function.

The following is discussed in two cases: one case is that there is no cooperation between the producer and manager; another is the opposite situation.

In each case, we assume that the form of the contract is linear:

$$
\begin{aligned}
& w_{1}=z_{1}+s_{1} q_{1}+t_{1} q_{2}, \\
& w_{2}=z_{2}+s_{2} q_{2}+t_{2} q_{1} .
\end{aligned}
$$

Among them, $z_{i}(i=1,2)$ represents fixed remuneration, $s_{i}\left(0 \leq s_{i} \leq 1, i=1,2\right)$ represents the share proportion of his own output, $t_{i}\left(0 \leq t_{i} \leq 1, i=1,2\right)$ represents the share proportion of other's output, $q_{i}(i=1,2)$ represents random output, $q_{i}=a_{i}+\varepsilon_{i}, \varepsilon_{i}(i=1,2)$ obeys the distribution in which the mean is zero, variance and covariance are as follows:

$$
\begin{aligned}
& \left(\begin{array}{cc}
\sigma_{1}^{2} & \sigma_{12} \\
\sigma_{12} & \sigma_{2}^{2}
\end{array}\right) \\
& \rho=\frac{\sigma_{12}}{\sigma_{1} \sigma_{2}},
\end{aligned}
$$

and $\rho$ represents the correlation coefficient between the two variables.

2.1. There Is No Partnership between the Producer and the Manager. In this case, the client signs a contract with the producer and the manager, respectively. When there is no relationship between the producer and the manager, they respond on each other's behavior by noncooperative game way [20].

The client maximizes the expected net income with the optimal choice $\left(z_{i}, s_{i}, t_{i}\right)(i=1,2)$ :

$$
V=\left(1-s_{1}-t_{2}\right) a_{1}+\left(1-s_{2}-t_{1}\right) a_{2}-z_{1}-z_{2} .
$$

Under the linear incentive contract, the equivalent welfare formulas of the agents are as follows:

$$
\begin{aligned}
\mathrm{CE}_{1}\left(a_{1}, a_{2}\right)= & z_{1}+s_{1} a_{1}+t_{1} a_{2}-\psi_{1}\left(a_{1}\right) \\
& -\frac{\eta_{1}}{2}\left(s_{1}^{2} \sigma_{1}^{2}+t_{1}^{2} \sigma_{2}^{2}+2 s_{1} t_{1} \sigma_{12}\right), \\
\mathrm{CE}_{2}\left(a_{1}, a_{2}\right)= & z_{2}+s_{2} a_{2}+t_{2} a_{1}-\psi_{2}\left(a_{2}\right) \\
& -\frac{\eta_{2}}{2}\left(s_{2}^{2} \sigma_{2}^{2}+t_{2}^{2} \sigma_{1}^{2}+2 s_{2} t_{2} \sigma_{12}\right) .
\end{aligned}
$$

The total welfare of the agents is as follows:

$$
\begin{aligned}
\mathrm{CE}_{1}+\mathrm{CE}_{2}= & z_{1}+s_{1} a_{1}+t_{1} a_{2}-\psi_{1}\left(a_{1}\right) \\
& -\frac{\eta_{1}}{2}\left(s_{1}^{2} \sigma_{1}^{2}+t_{1}^{2} \sigma_{2}^{2}+2 s_{1} t_{1} \sigma_{12}\right)+z_{2}+s_{2} a_{2} \\
& +t_{2} a_{1}-\psi_{2}\left(a_{2}\right)-\frac{\eta_{2}}{2}\left(s_{2}^{2} \sigma_{2}^{2}+t_{2}^{2} \sigma_{1}^{2}+2 s_{2} t_{2} \sigma_{12}\right) .
\end{aligned}
$$


According to the incentive constraints, under Nash equilibrium state the choice of the agents is as follows:

$$
a_{i}=\arg \max _{\hat{a}_{i}} \mathrm{CE}_{i}\left(\hat{a}_{i}, a_{j}\right) \quad i=1,2 ; j=2,1 .
$$

And the individual rationality constraints are $\mathrm{CE}_{i}\left(a_{i}\right.$, $\left.a_{j}\right) \geq 0, \quad i=1,2 ; j=2,1$.

Namely, the first-order conditions are as follows:

$$
\begin{aligned}
& \frac{\partial \mathrm{CE}_{1}\left(a_{1}, a_{2}\right)}{\partial a_{1}}=0 \\
& \frac{\partial \mathrm{CE}_{2}\left(a_{1}, a_{2}\right)}{\partial a_{2}}=0 .
\end{aligned}
$$

We will get the following conclusions:

$$
\begin{aligned}
& s_{1}=\psi_{1}^{\prime}\left(a_{1}\right), \\
& s_{2}=\psi_{2}^{\prime}\left(a_{2}\right) .
\end{aligned}
$$

Proposition 1. The action choice $a_{i}$ of the producer and the manager and the share proportion of his own output are closely associated.

Then, to minimize the risk of the agents we make the following assumptions:

$$
\begin{aligned}
& t_{1}=-s_{1} \frac{\sigma_{1}}{\sigma_{2}} \rho, \\
& t_{2}=-s_{2} \frac{\sigma_{2}}{\sigma_{1}} \rho .
\end{aligned}
$$

Substituting formula (10) and $\sigma_{12}=\rho \sigma_{1} \sigma_{2}$ into the risk part of formula (6), we will obtain the sum of two individual risks:

$$
\frac{1}{2}\left(1-\rho^{2}\right)\left(\eta_{1} s_{1}^{2} \sigma_{1}^{2}+\eta_{2} s_{2}^{2} \sigma_{2}^{2}\right)
$$

2.2. There Is a Cooperative Relationship between the Producer and the Manager. In this case, there is a contractual relationship between the producer and the manager; they can coordinate the actions with the contract.

At this time, the transfer payment between the producer and the manager is $\left(\lambda q_{1}+\gamma q_{2}\right)$, which can be offset by the client through the following series of predetermined assumptions:

$$
\begin{aligned}
& s_{1} \text { becomes } s_{1}^{\prime}=s_{1}-\lambda \\
& t_{2} \text { becomes } t_{2}^{\prime}=t_{2}+\lambda \\
& t_{1} \text { becomes } t_{1}^{\prime}=t_{1}-\gamma \\
& s_{2} \text { becomes } s_{2}^{\prime}=s_{2}+\gamma .
\end{aligned}
$$

So we will have that

$$
\begin{aligned}
w_{1}^{\prime}+w_{2}^{\prime}= & z_{1}+s_{1}^{\prime} q_{1}+t_{1}^{\prime} q_{2}+z_{2}+s_{2}^{\prime} q_{1}+t_{2}^{\prime} q_{2} \\
= & z_{1}+\left(s_{1}-\lambda\right) q_{1}+\left(t_{1}-\gamma\right) q_{2}+z_{2} \\
& +\left(s_{2}+\gamma\right) q_{2}+\left(t_{2}+\lambda\right) q_{1} \\
= & w_{1}+w_{2} \\
V^{\prime}= & {\left[1-\left(s_{1}-\lambda\right)-\left(t_{2}+\lambda\right)\right] a_{1} } \\
& +\left[1-\left(s_{2}+\gamma\right)-\left(t_{1}-\gamma\right)\right] a_{2}-z_{1}-z_{2} \\
= & V .
\end{aligned}
$$

Proposition 2. Whether the basis of the cooperation between the producer and the manager is $\left(a_{1}, a_{2}\right)$ or $\left(a_{1}, a_{2}, q_{1}, q_{2}\right)$, the optimal contract and the expected net income of the client are the same.

The producer and the manager face the given incentive mechanism $\left(s_{i}, t_{i}\right)(i=1,2)$; their responses are to maximize the joint welfare:

$$
\begin{gathered}
\max _{\lambda, \gamma, a_{i}} z_{1}+z_{2}+\left(s_{1}+t_{2}\right) a_{1}+\left(s_{2}+t_{1}\right) a_{2} \\
-\psi_{1}\left(a_{1}\right)-\psi_{2}\left(a_{2}\right) \\
-\frac{\eta_{1}}{2}\left[\left(s_{1}-\lambda\right)^{2} \sigma_{1}^{2}+\left(t_{1}-\gamma\right)^{2} \sigma_{2}^{2}\right. \\
\left.+2\left(s_{1}-\lambda\right)\left(t_{1}-\gamma\right) \sigma_{12}\right] \\
-\frac{\eta_{2}}{2}\left[\left(s_{2}+\gamma\right)^{2} \sigma_{2}^{2}+\left(t_{2}+\lambda\right)^{2} \sigma_{1}^{2}\right. \\
\left.+2\left(s_{2}+\gamma\right)\left(t_{2}+\lambda\right) \sigma_{12}\right] .
\end{gathered}
$$

Obviously, the client wants to maximize the benefit by selecting $\left(s_{i}, t_{i}\right)(i=1,2)$ and forecasting $\left(\lambda, \gamma, a_{1}, a_{2}\right)$.

As a result, the given incentive mechanism $\left(s_{i}, t_{i}\right)(i=$ $1,2)$ is converted to their effort level and risk sharing; then transfer payment can minimize the risk of the producer and the manager. Namely,

$$
\begin{aligned}
& \frac{\partial\left(\mathrm{CE}_{1}+\mathrm{CE}_{2}\right)}{\partial \lambda}=0, \\
& \frac{\partial\left(\mathrm{CE}_{1}+\mathrm{CE}_{2}\right)}{\partial \gamma}=0 .
\end{aligned}
$$

So we deduce that

$$
\begin{gathered}
\lambda=\frac{\eta_{1} s_{1}-\eta_{2} t_{2}}{\eta_{1}+\eta_{2}} \\
\gamma=\frac{\eta_{1} t_{1}-\eta_{2} s_{2}}{\eta_{1}+\eta_{2}} \\
s_{1}-\lambda=\frac{\eta_{2}}{\eta_{1}+\eta_{2}}\left(s_{1}+t_{2}\right)
\end{gathered}
$$




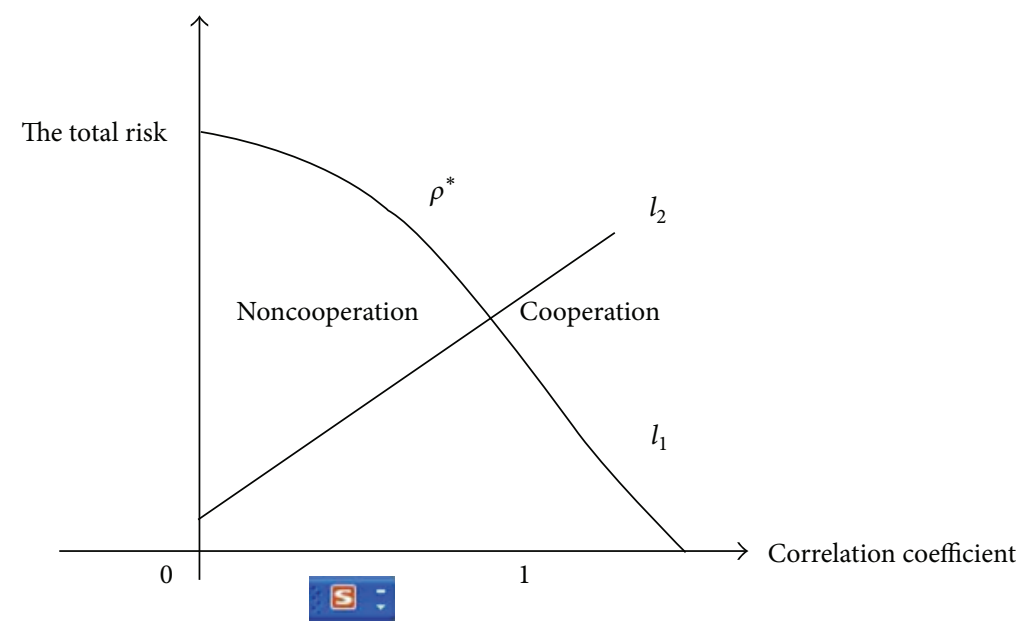

Figure 1: The relationship between the total risk and the correlation coefficient $\rho$. Notes. Curve 1 indicates the sum of optimal risks when having the cooperation between the manager and the producer; Curve 2 indicates the sum when having no cooperation.

$$
\begin{aligned}
& t_{1}-\gamma=\frac{\eta_{2}}{\eta_{1}+\eta_{2}}\left(t_{1}+s_{2}\right) \\
& s_{2}+\gamma=\frac{\eta_{1}}{\eta_{1}+\eta_{2}}\left(t_{1}+s_{2}\right) \\
& t_{2}+\lambda=\frac{\eta_{1}}{\eta_{1}+\eta_{2}}\left(s_{1}+t_{2}\right) .
\end{aligned}
$$

Thus, the sum of two agents' optimal risk is

$$
\begin{gathered}
\frac{\eta_{1}}{2\left(\eta_{1}+\eta_{2}\right)^{2}}\left[\eta_{2}^{2}\left(s_{1}+t_{2}\right)^{2} \sigma_{1}^{2}+\eta_{2}^{2}\left(t_{1}+s_{2}\right)^{2} \sigma_{2}^{2}\right. \\
\left.+2 \eta_{2}^{2}\left(s_{1}+t_{2}\right)\left(t_{1}+s_{2}\right) \sigma_{12}\right] \\
+\frac{\eta_{2}}{2\left(\eta_{1}+\eta_{2}\right)^{2}}\left[\eta_{1}^{2}\left(t_{1}+s_{2}\right)^{2} \sigma_{2}^{2}+\eta_{1}^{2}\left(s_{1}+t_{2}\right)^{2} \sigma_{1}^{2}\right. \\
\left.+2 \eta_{1}^{2}\left(t_{1}+s_{2}\right)\left(s_{1}+t_{2}\right) \sigma_{12}\right] .
\end{gathered}
$$

It is simplified as follows:

$$
\begin{array}{r}
\frac{1}{2} \frac{\eta_{1} \eta_{2}}{\left(\eta_{1}+\eta_{2}\right)}\left[\left(s_{1}+t_{2}\right)^{2} \sigma_{1}^{2}+\left(t_{1}+s_{2}\right)^{2} \sigma_{2}^{2}\right. \\
\left.+2\left(s_{1}+t_{2}\right)\left(t_{1}+s_{2}\right) \sigma_{12}\right] .
\end{array}
$$

Let $\eta_{1} \eta_{2} /\left(\eta_{1}+\eta_{2}\right)$ be $\eta$; we will have the following proposition.

Proposition 3. The total risk of the producer and the manager can be viewed as the one of a person with the risk aversion coefficient $\eta$ having the share $\left(s_{1}+t_{2}, t_{1}+s_{2}\right)$.

Proposition 4. If and only if $0 \leq \rho \leq \rho^{*} \leq 1$, the optimal risk and the joint welfare sum with the cooperation between the manager and the producer are better than no cooperation.

Proof. Firstly, we assume that the incentive levels are all $\left(s_{1}, s_{2}\right)$ in order to achieve the same effort level $\left(a_{1}, a_{2}\right)$.
In addition, we let $t_{1}$ and $t_{2}$ be zero and bring in variables $(\lambda, \gamma)$ to minimize the total risk when having a partnership between the manager and the producer.

We obtain that the total risk is

$$
\frac{1}{2} \frac{\eta_{1} \eta_{2}}{\left(\eta_{1}+\eta_{2}\right)}\left[s_{1}^{2} \sigma_{1}^{2}+s_{2}^{2} \sigma_{2}^{2}+2 s_{1} s_{2} \rho \sigma_{1} \sigma_{2}\right]
$$

when $\rho=0$, formula (11) minus (19), and the answer is

$$
\frac{1}{2}\left(\frac{\eta_{1}^{2}}{\eta_{1}+\eta_{2}}\right) s_{1}^{2} \sigma_{1}^{2}+\frac{1}{2}\left(\frac{\eta_{2}^{2}}{\eta_{1}+\eta_{2}}\right) s_{2}^{2} \sigma_{2}^{2}>0 .
$$

So when $\rho=0$, the optimal risk with the cooperation between the manager and the producer is better than no cooperation.

When $\rho=1$, formula (11) is zero and formula (19) is

$$
\frac{1}{2} \frac{\eta_{1} \eta_{2}}{\left(\eta_{1}+\eta_{2}\right)}\left[s_{1}^{2} \sigma_{1}^{2}+s_{2}^{2} \sigma_{2}^{2}+2 s_{1} s_{2} \sigma_{1} \sigma_{2}\right] \text {. }
$$

At this time, formula (11) is less than (19).

Obviously, as shown in Figure 1, formula (11) decreases with the increase of $\rho$; formula (19) increases with the increase of $\rho$.

Therefore, there will be $\rho^{*}$, if and only if $0 \leq \rho \leq \rho^{*} \leq 1$; the optimal risk with the cooperation between the manager and the producer is better than noncooperation.

According to the above analysis, when $\rho=0$, the sum of welfare with the cooperation between the manager and the producer is less than noncooperation.

When $\rho=1$, the sum of welfare with the cooperation between the manager and the producer is more than noncooperation.

When $0 \leq \rho \leq 1$, Formula (6) increases with the increase of $\rho$ and Formula (14) decreases with the increase of with $\rho$.

Similarly, there will be $\rho^{*}$, if and only if $0 \leq \rho \leq \rho^{*} \leq 1$; the sum of welfare with the cooperation between the manager and the producer is more than the one with noncooperation.

This shows that when $0 \leq \rho \leq \rho^{*} \leq 1$, the cooperation between the manager and the producer brings more benefits. But when $\rho>\rho^{*}$, they will choose to give up the cooperation. 


\section{Cooperative Game Model Based on the Theory of Enterprise Power Distribution}

In the game model, we first treat "power" as "alternative degree" and "the proportion of profit distribution," further regard "alternative degree" as "bargaining power," and then look on "bargaining power" as "the cost of repurchasing." Thus, we can discuss "power" with the framework of cooperative game theory in standard economic theory.

3.1. The Cooperative Game Process of Internal Power Allocation and the Critical State. We use production function with the fixed proportions (CES):

$$
y=f(k, l)=\min (k, l) .
$$

Assume that the price of human capital $k$ and labor $l$ is $p_{k}$ and $p_{l}$, respectively. The manager and the producer with their cooperation bring the total profit $\pi$ which is constant, $\lambda(0 \leq$ $\lambda \leq 1)$ means the share of profit for the manager, and $1-\lambda$ means the proportion for the producer. The ratio of corporate profit is distributed according to the size of internal control. The greater the owner of the element has corporate control, the more he shares the portion of the profit. The participants' revenue is composed of the income which is decided by the market price and the share of the profit. Therefore, when the manager chooses cooperation, the principal will sign the following contract with him:

$$
\pi_{k 1}=p_{k} k+\lambda \pi .
$$

And when the producer chooses cooperation, the contract is

$$
\pi_{l 1}=p_{l} l+(1-\lambda) \pi .
$$

If one side of the manager and the producer does not choose to cooperate, the other one can only purchase the factors of production which he lacks. The people who buy the factor will hold actual control rights and receive all the profit when the owner of the factor has no bargaining power. Let $c_{i}(i=k, l)$ mean the replacement cost. At this time, the contracts of the manager and the producer are as follows separately:

$$
\begin{aligned}
& \pi_{k 2}=p_{k} k+\pi-l c_{l}, \\
& \pi_{l 2}=p_{l} l+\pi-k c_{k} .
\end{aligned}
$$

The manager chooses to cooperate with the producer under the condition:

$$
p_{k} k+\lambda \pi \geq p_{k} k+\pi-l c_{l} .
$$

Similarly, the producer chooses to cooperate with the manager under the condition:

$$
p_{l} l+(1-\lambda) \pi \geq p_{l} l+\pi-k c_{k} .
$$

According to the above two formulas, we conclude that

$$
1-\frac{l c_{l}}{\pi} \leq \lambda \leq \frac{k c_{k}}{\pi} .
$$

Then we have the following.
Proposition 5. If $c_{l} \rightarrow 0$, then $\lambda \rightarrow 1, k c_{k} \rightarrow \pi$.

This suggests that when the manager does not cooperate with the producer and repurchases labor element in the market and the replacement cost of labor is close to zero, the manager will grasp the actual control right and have almost all of the profit.

Proof. Because $\lim _{c_{l} \rightarrow 0} 1-l c_{l} / \pi=1,0 \leq \lambda \leq 1$, and $1-l c_{l} / \pi \leq$ $\lambda \leq k c_{k} / \pi$, hence we have $\lim _{c_{l} \rightarrow 0} \lambda=\lim _{c_{l} \rightarrow 0} k c_{k} / \pi=1$, which is based on the limit criterion.

Therefore, if $c_{l} \rightarrow 0$, then $\lambda \rightarrow 1, k c_{k} \rightarrow \pi$.

Similar to the proof of Proposition 5, we may prove the following result.

Proposition 6. If $c_{k} \rightarrow 0$, then $\lambda \rightarrow 1, l c_{l} \rightarrow \pi$.

In the same way, when the producer does not cooperate with the manager and repurchase human capital resources in the market, and the replacement cost of the capital is close to zero, the producer will grasp the actual control right and have almost all of the profit.

The above analysis is purely based on the theory. But in fact, the replacement cost of human capital is high and the replacement cost of labor is low. So the owners of human capital in modern company have more control.

\subsection{The Optimal Allocation of the Profit \\ Distribution and Control between the Manager and the Producer When Having the Cooperation}

Case 1. Bargaining power and enterprise internal power of the manager and the producer are the same.

Based on the Nash bargaining solution, on the assumption that the two sides are symmetrical, the proportion of profit distribution meets the following condition:

$$
\lambda=\arg \max \left[\left(\pi_{l 1}-\pi_{l 2}\right)^{1 / 2}\left(\pi_{k 1}-\pi_{k 2}\right)^{1 / 2}\right] .
$$

Among them, $\left[\left(\pi_{l 1}-\pi_{l 2}\right)^{1 / 2}\left(\pi_{k 1}-\pi_{k 2}\right)^{1 / 2}\right]$ means Nash product.

$$
\begin{aligned}
& \text { Let }\left[\left(\pi_{l 1}-\pi_{l 2}\right)^{1 / 2}\left(\pi_{k 1}-\pi_{k 2}\right)^{1 / 2}\right]=v \text {; we have that } \\
& \qquad \ln v=\frac{1}{2} \ln \left(\pi_{l 1}-\pi_{l 2}\right)+\frac{1}{2} \ln \left(\pi_{k 1}-\pi_{k 2}\right) .
\end{aligned}
$$

Obviously, $\lambda=\arg \max (\ln v)$.

Substituting formulas (23)-(25) into formula (30), we will obtain that

$$
\ln v=\frac{1}{2} \ln \left(-\lambda \pi+k p_{k}\right)+\frac{1}{2} \ln \left(\lambda \pi-\pi+l p_{l}\right) .
$$

Take derivatives on the two sides of (31) and let the derivative be zero; we will get the result of the calculation:

$$
\begin{gathered}
\frac{1}{2} \frac{-\pi}{-\lambda \pi+k p_{k}}+\frac{1}{2} \frac{\pi}{\lambda \pi-\pi+l p_{l}}=0, \\
\lambda=\frac{1}{2}+\frac{k p_{k}-l p_{l}}{2 \pi} .
\end{gathered}
$$


Case 2. Bargaining power and enterprise internal power of the manager and the producer are not the same.

(1) Considering Bargaining Power. We think bargaining power itself is a direct proportion function of the replacement cost. Concretely, the lower the repurchase cost, the higher alternative degree of the element in the market, the lower the bargaining power. So we assume that

$$
\alpha=a p_{k}, \quad \alpha^{\prime}=a^{\prime} p_{l} .
$$

Among them, $\alpha$ and $\alpha^{\prime}$ mean bargaining power and exogenous variables. $\alpha+\alpha^{\prime}=1, \alpha>0, \alpha^{\prime}>0, a$ and $a^{\prime}$ are proportional coefficients.

Similarly,

$$
\begin{gathered}
\lambda=\arg \max \left[\left(\pi_{l 1}-\pi_{l 2}\right)^{\alpha}\left(\pi_{k 1}-\pi_{k 2}\right)^{\alpha^{\prime}}\right] \\
{\left[\left(\pi_{l 1}-\pi_{l 2}\right)^{\alpha}\left(\pi_{k 1}-\pi_{k 2}\right)^{\alpha^{\prime}}\right]=v^{\prime},} \\
\ln v^{\prime}=\alpha \ln \left(\pi_{l 1}-\pi_{l 2}\right)+\alpha^{\prime} \ln \left(\pi_{k 1}-\pi_{k 2}\right) \\
\lambda=a p_{k}+\frac{k p_{k}-a p_{k}\left(k p_{k}+l p_{l}\right)}{\pi} .
\end{gathered}
$$

(2) Considering Enterprise Internal Power. In the framework of our model, the ratio of corporate profit allocation is determined by the internal control size, specifically as follows: the greater the owner of the elements has the control, the more share of profits will be. Consequently, there is a corresponding relationship between the control size of the owner and the share proportion of profits. Let $D_{i}(i=k, l)$ be the control size of the element owners and $b, b^{\prime}$ proportional coefficients; we will have that

$$
\begin{gathered}
\lambda=f\left(D_{k}\right)=b D_{k} \\
1-\lambda=f\left(D_{l}\right)=b^{\prime} D_{l} \\
D_{k}=\frac{b \pi}{\left[a p_{k}\left(\pi-k p_{k}-l p_{l}\right)+k p_{k}\right]} \\
D_{l}=\frac{b^{\prime} \pi}{\left(1-a p_{k}\right)\left(\pi-k p_{k}\right)+a p_{k} l p_{l}} .
\end{gathered}
$$

\section{Conclusions}

In this paper, based on the principal-agent theory, a cooperative game model is constructed under the liner contract condition. Combined with the model, we build two possible scenarios, one is when the manager and the producer having the cooperation, the other is the opposite situation. We come to the following conclusions. The action choice $\alpha_{i}$ of the producer and the manager and the share proportion from their own output are closely associated. Whether the basis of the cooperation between them is $\left(\alpha_{1}, \alpha_{2}\right)$ or $\left(\alpha_{1}, \alpha_{2}, q_{1}, q_{2}\right)$, the client can get the same optimal contract and expected net income. In addition, correlation coefficient $\rho$ between the outputs of the manager and the producer decides whether they will have the cooperation or not. The result shows that

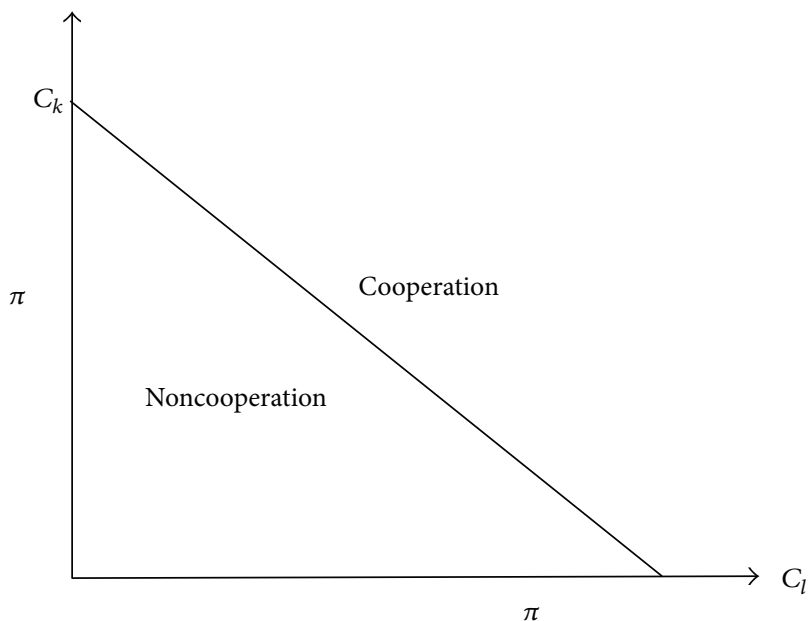

FIGURE 2: The choice of area of cooperation and noncooperation between the manager and the producer.

when $0 \leq \rho \leq \rho^{*} \leq 1$, the cooperation between the manager and the producer brings more benefits. However, when $\rho>\rho^{*}$, they will choose to give up the cooperation. Another model about the manager and the producer is established with the theory of enterprise power distribution. We specifically analyze the cooperative game process and the critical state. Their cooperation conditions are shown in Figure 2. We find out the optimal share of their output and control when the manager and the producer have the cooperation.

This paper establishes the game models and methods, which greatly expands the research depth and scope of management game problems and thus for people provides a new theoretical tool to study complex game problems.

\section{Conflict of Interests}

The author declares that there is no conflict of interests regarding the publication of this paper.

\section{References}

[1] B. Stanley, J. H. May, and A. Mukerji, "Optimal employment contracts and the returns to monitoring in a principal- agent context," Contemporary Accounting Research, vol. 6, no. 2, pp. 761-799, 1990.

[2] O. Hart and J. Moore, "Contracts as reference points," Quarterly Journal of Economics, vol. 123, no. 1, pp. 1-48, 2008.

[3] W. Y. Zhang, Game Theory and Information Economics, Shanghai People's Publishing House, 1996.

[4] J. W. Friedam, Game Theory with Applications of Economics, MIT Press, 1990.

[5] M. Aoki, The Co-Operative Game Theory of the Firm, Oxford University Press, Oxford, UK, 1984.

[6] J. F. Mertens, "Ordinality in non cooperative games," International Journal of Game Theory, vol. 32, no. 3, pp. 387-430, 2003.

[7] J. Nash, “The bargaining problem," Econometrica, vol. 18, pp. 155-162, 1950. 
[8] Z. S. Chen and X. K. Yang, "Enterprises in the market: a noncooperative bargaining repeated game," Management World, no. 7, pp. 116-125, 1997.

[9] A. Rubinstein, "A bargaining model with incomplete information about time preferences," Econometrica, vol. 53, no. 5, pp. 1151-1172, 1985.

[10] J. C. Jing, "Game balance of stakeholders and management performance of businesses," Journal of Sichuan University, no. 4, pp. 125-131, 2004.

[11] H. P. Wang, "Game analysis of stakeholders in financial conflicts of interest," Modern Business Trade Industry, no. 8, pp. 159-160, 2010.

[12] Z. Y. Liu, "The government and the enterprise: interest game and moral game," Political Studies, vol. 5, pp. 121-128, 2006.

[13] J. Jiao, "Conflict of interest game and the legal solutions," Forward Position, no. 15, pp. 61-64, 2010.

[14] A. Rubinstein, "Perfect equilibrium in a bargaining model," Econometrica, vol. 50, no. 1, pp. 97-109, 1982.

[15] Y. M. Xu, "Firms distribution theory based on cooperative game," Journal of Hunan University (Social Sciences), vol. 20, no. 5, pp. 73-78, 2006.

[16] H. Zhao, "Cooperative Game and Equilibrium among Stakeholders," The Theory and Practice of Finance and Economics, vol. 28, no. 148, pp. 74-77, 2007.

[17] W. Sun, J. F. Zhang, and H. X. Li, "Research on benefit main body gambling of stakeholders based on moral element," Chinese Journal of Management Science, vol. 19, pp. 152-155, 2011.

[18] B. Holmstrom and P. Milgrom, "Regulating trade among agents," Journal of Institutional and Theoretical Economics, vol. no. 146, pp. 85-105, 1990.

[19] P. Bolton and M. Dewatripont, Contract Theory, MIT Press, 2005.

[20] G. M. Hou and C. J. Li, "The mechanism expression of incooperative game in management," Chinese Journal of Management Science, vol. 10, no. 3, pp. 86-90, 2002. 


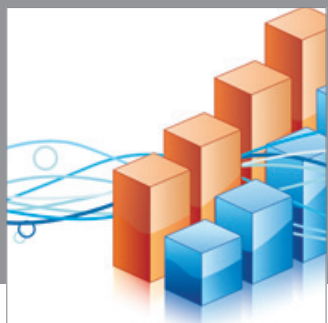

Advances in

Operations Research

mansans

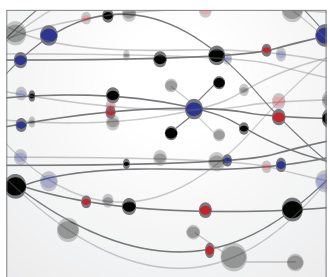

The Scientific World Journal
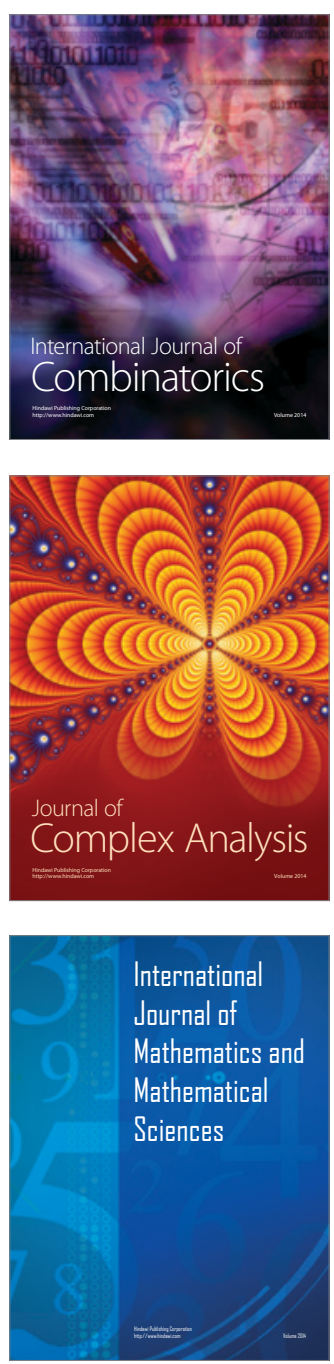
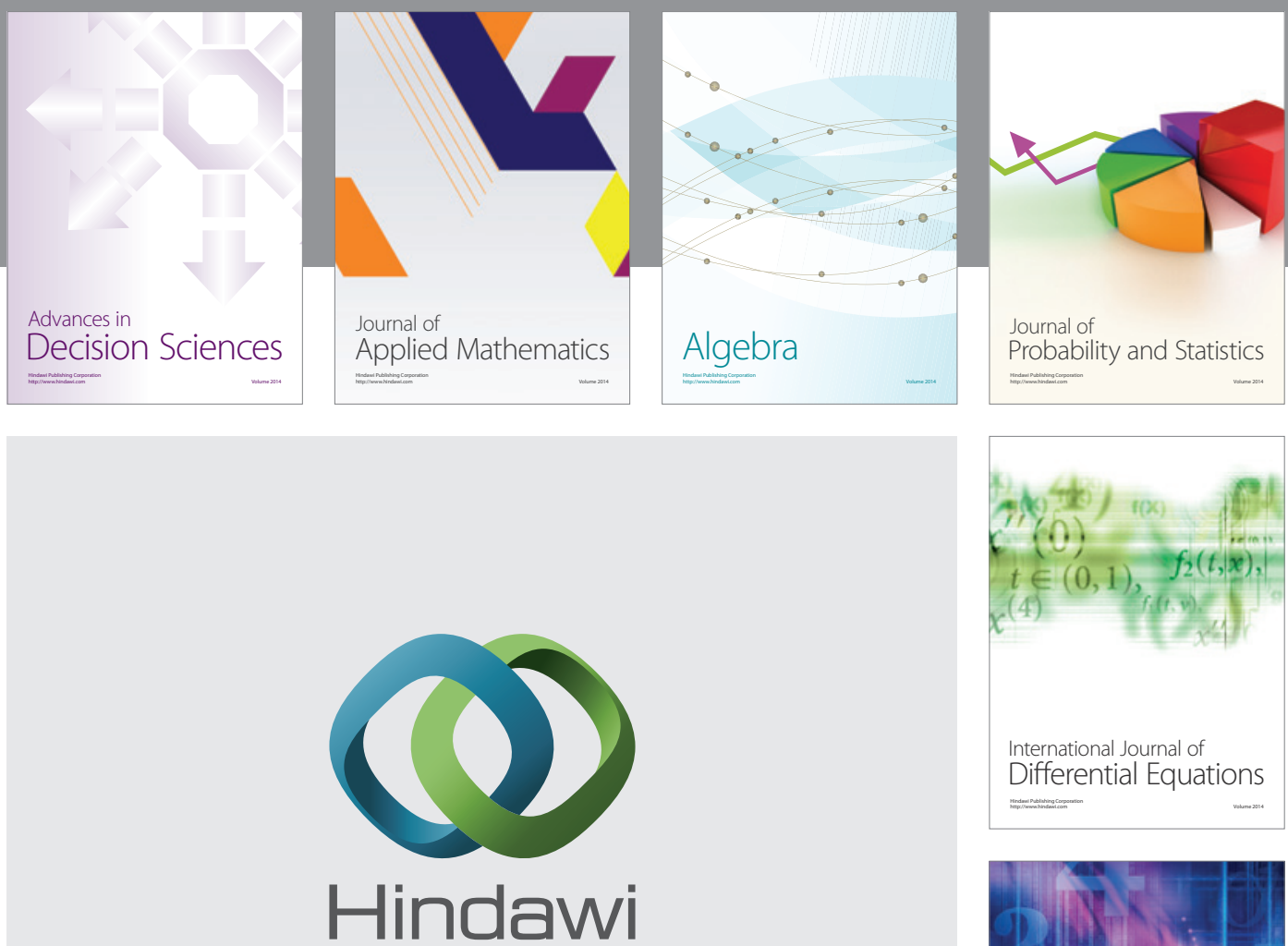

Submit your manuscripts at http://www.hindawi.com
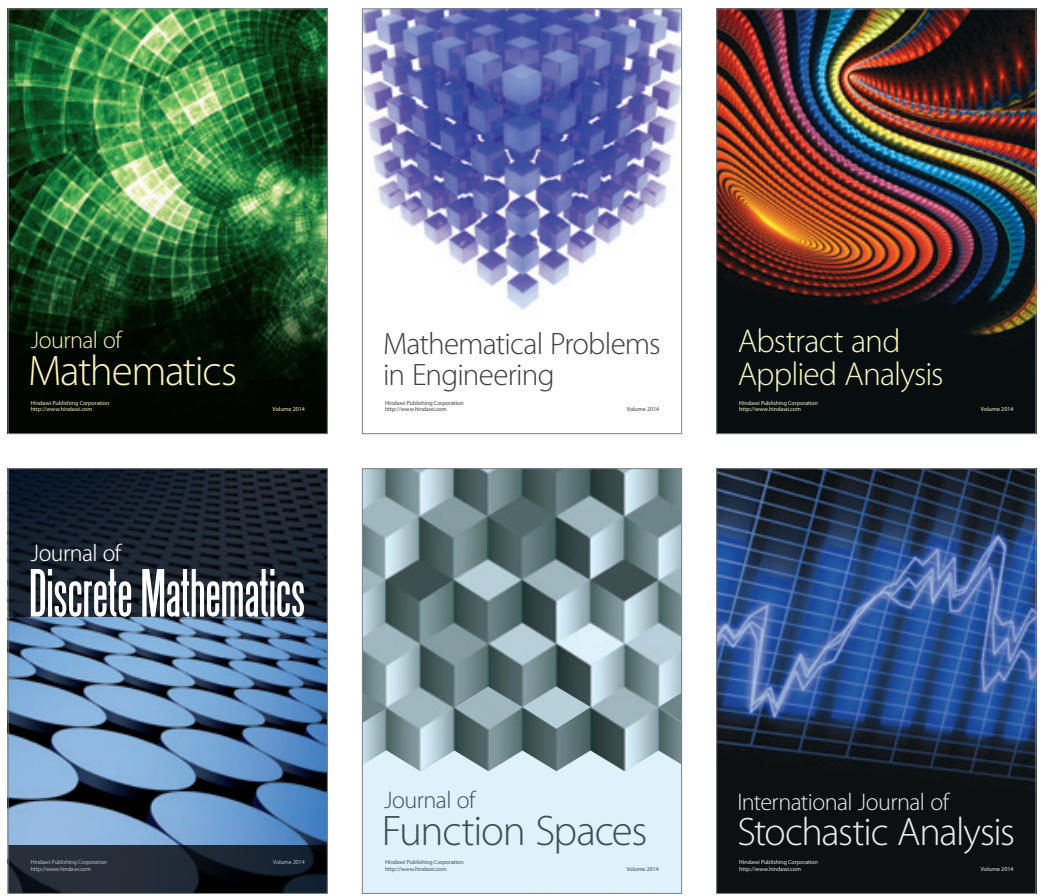

Journal of

Function Spaces

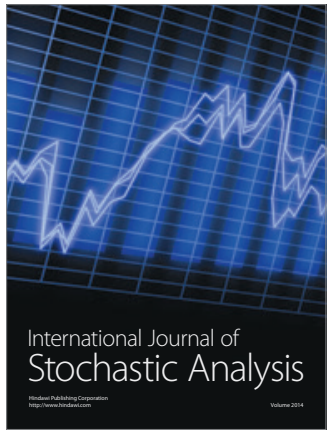

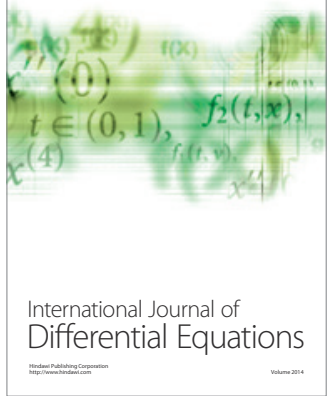
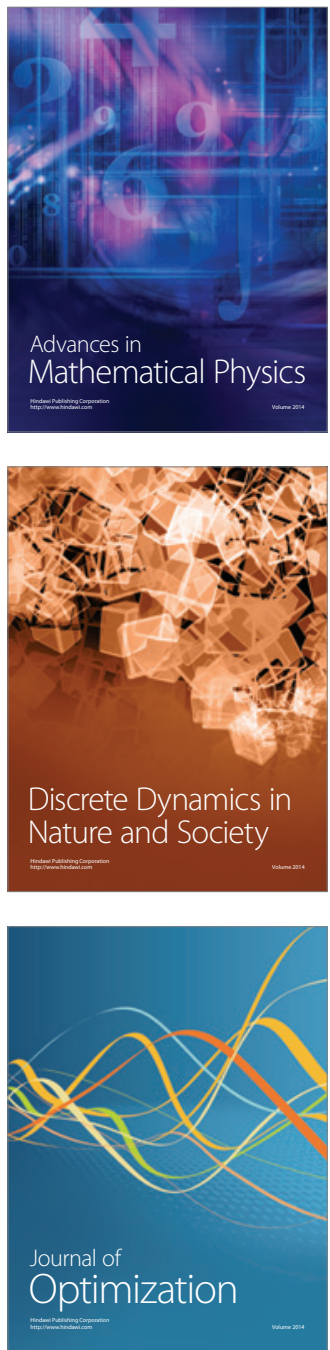